\title{
Invited Articles from 2016 ICFSMA
}

\author{
Ryosuke Kainuma ${ }^{1}$
}

Published online: 19 July 2017

(c) ASM International 2017

During the last 20 years, Ferromagnetic Shape Memory Alloys (FSMAs), such as Ni-Mn-Ga, Ni-Mn-In and FePd alloys, receive a great attention as an interdisciplinary research-field between martensitic and magnetic transformations and recently, the field expands to caloric effects, such as magnetocaloric and mechanocaloric effects, which receive a keen attention as a new solid-refrigeration technology. Since the first International Conference on FSMAs in Kolkata, India, in 2007, the series of "International Conference on Ferromagnetic Shape Memory Alloys (ICFSMA)" were held in Bilbao, Spain in 2009, Dresden, Germany in 2011 and Boise, United States in 2013, providing new and exciting aspects of magnetic SM alloys as the key conference in this field. In 2016, we have held the 5th ICFSMA on 5 to 9 September at Sendai, Japan with almost 100 participants from all over the world. The Special Issue is to memorialize the fruitful conference and composed of original or review articles written by the

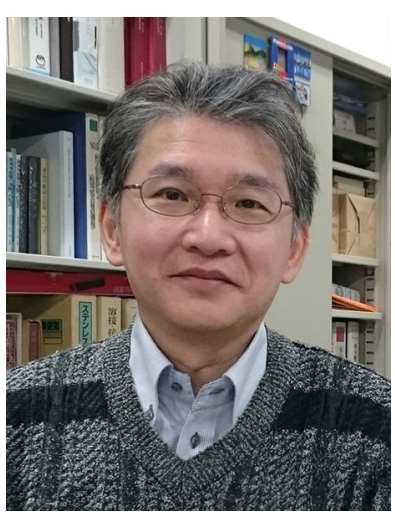

Prof. Dr. Ryosuke Kainuma Guest Editor

authors selected and invited from presenters in the 5th ICFSMA. I want to thank all the contributors and the journal editor for their effort to complete the Special Issue.

Ryosuke Kainuma

kainuma@material.tohoku.ac.jp

1 Department of Materials Science, Graduate School of Engineering, Tohoku University, Sendai, Japan 